\title{
CONOCIMIENTO FRENTE A EXPERIENCIA EN EL PRIMER ACTO DE CELESTINA: UNA POSIBLE DISCORDANCIA TEMÁTICA
}

\author{
Francisco Layna Ranz \\ Madrid
}

Inicia Rojas su prólogo a Celestina con una alusión al carácter de contienda que tiene todo lo existente en este mundo, y apoya su aserto en una autoridad de calado y raigambre filosófica: "todas las cosas ser criadas a manera de contienda o batalla, dize aquel gran sabio Eráclito en este modo: omnia secundum litem fiunt." La naturaleza de este arranque es de un orden habitual en las aulas universitarias, cuya actividad académica discurría entre disputas y apelaciones a los autores de la Antigüedad. Todo se rige bajo las leyes del debate y el litigio, y esto es algo respaldado por aquella sabiduría que nos legó los límites del mundo, y para evitar que se abrigue duda de falsedad o inexactitud, ahí está la cita de Heráclito en latín, inundando lo dicho de circunspecta erudición. Inapelable el arranque de Rojas, retórico y escolástico hasta la médula.

No obstante, el prólogo dará paso a una historia trágica de amor, un sucedido donde lo que impera es la expresión y el fruto del deseo, así como el poder casi sin límites de la experiencia. Sabiduría y experiencia son realidades que igualmente entrarían dentro de ese ámbito dominado por la dinámica de la disputa, ambas regidas por los requisitos de la antigüedad y capacidad para ofrecer soluciones a los conflictos. El estudiante salmantino tenía en sus manos uno de los dilemas más vigentes entre sus contemporáneos: que sabiduría y verdad no siempre corren parejas, y que la fuente de autoridad se ve reducida a un mero recurso del vano retoricismo que alcanzaba a todo tipo de argumentación. Este conflicto, formulado desde las primeras líneas del primer acto mediante la oposición entre doctrina y experiencia, en la Tragicomedia se difumina y diluye en una acción posterior distante de la exposición inicial. 


\section{PRIMER ACTO DE CELESTINA. Introducción}

Poco después de ser descubierta en 1433, la obra del gramático Aelio Donato pasó a ser obligado referente para las aplicaciones de la retórica clásica a la obra de Terencio.' El propósito fundamental de Donato era el análisis de la comedia desde una perspectiva retórica, y, más en concreto, la relación de Terencio con las teorías de Cicerón y Quintiliano. Suele decirse que sería de gran utilidad conocer cuál fue la lectura que el autor de Celestina hizo de las seis comedias de Terencio. Además, y aunque aún no poseamos la documentación que lo acredite, Donato pudo muy bien haber sido uno de esos comentaristas que facilitaron, y tal vez determinaron, su recepción en las aulas salmantinas. ${ }^{2}$ En el siglo XVI es palmario el fruto de esta relación del hecho teatral con las prácticas argumentativas de las escuelas. Sirva de ejemplo que, en la edición de 1570 de Terencio, Vicentius Cordatus analizaba su primera comedia, Andria, como una disputa entre hombres jóvenes y viejos, cuyo asunto consistía en la pertinencia o no del matrimonio.

El uso de la retórica es uno de los aspectos más y mejor estudiados de Celestina. ${ }^{3}$ De un tiempo a esta parte se nos previene que este despliegue

' Donati... commentum Terenti, Leipzig: Teubneriana, 1902-1905.

${ }^{2}$ Charles F. Fraker, "Rhetoric in the Celestina: Another Look," en Aureum Saeculum Hispanum. Beiträge zu Texten des Siglo de Oro (Festschrift für Hans Flasche zum 70. Geburtstag) (Wiesbaden: F. Steiner, 1983), 81-90. Véase, para bibliografía relativa a Terencio y Donato, A. Stäuble, La commedia umanistica del Quattrocento (Firenze: Istituto Nazionale di Studio sul Rinascimento, 1968), $146 \mathrm{n} 1$.

${ }^{3}$ C. Samonà, Aspetti del retoricismo nella "Celestina", Roma: Fac. di Magisterio dell'Università, Studi di Letteratura Spagnola, 2, 1953; Charles F. Fraker (ver n2); C. F. Fraker, "Declamation and the Celestina,"Celestinesca9.2(1985),47-64;C. F. Fraker, "Celestina": Genre and Rhetoric, Londres: Tamesis, 1990; C. Faulhaber, "Retóricas clásicasy medievales en bibliotecas castellanas, "Ábaco4 (1973),206-242; G. A. Shipley, "Authority and Experience in La Celestina," Bulletin of Hispanic Studies 62 (1985), 95111; A. D. Deyermond, The Petrarchan Sources of 'La Celestina', Oxford: Oxford UP, 1961; E. Morgan, "Rhetorical Technique in the Persuasion of Melibea," Celestinesca 3.2(1979),7-18; O. Handy, "The Rhetorical and Psychological Defloration of Melibea," Celestinesca 7.1 (1983), 17-27; Malcolm K. Read, "Fernando de Rojas' Vision of the Birth and Death of Language,"ModernLanguageNotes 93 (1978), 163-175;M. K. Read, "The Rhetoric of Social Encounter: La Celestina and the Renaissance Philosophy of Language," en Birth and Death of Language:Spanish Literature and Linguistics, 13001700, Madrid: Porrúa, 1983, 70-96; P. E. Russell, "Discordia universal: La Celestina como 'Floresta de philosophos'," Ínsula, no. 497, (abril 1988), 1 y 3; D. S. Severin, Memory in "La Celestina", Londres: Tamesis, 1970; D. S. Severin, "Aristotle's Ethics and La Celestina, "La Corónica 10 (1981-1982),54-58; E. H. Friedman, "Rhetoric at 
retórico puede tener bastante poco de serio y mucho de recreación de métodos procedentes de las aulas. Sin duda en esta línea hay que situar aquella célebre perorata que Sempronio lanza a Calisto ya en el acto primero. Investido de categoría profesoral, aconseja el criado para la dolencia amorosa de su joven amo la lectura de Salomón, Séneca, Aristóteles, Bernardo 4 y la Biblia. Aunque de uso obligado en la tratadística amorosa, el manejo de auctores no parece muy apropiada solución para un asunto de lujuria. ${ }^{5}$ De hecho, un poco antes Sempronio había clamado por la frecuencia con que los amantes suelen desamparar a Dios y a su ley, aunque tal conducta no le extrañaba "pues los sabios, los santos, los profetas" también por cuestiones de amor se apartaron de la senda divina. ${ }^{6}$ Si también cayeron los sabios que Sempronio aconseja a Calisto para su mal, si de igual manera sucumbieron santos y profetas, ¿cuál es entonces la razón de ser de su propuesta?

Caben dos soluciones que en sí no son excluyentes: que se trate de un mero alarde libresco de tradición misógina, o que se intente enfatizar que los mismos sabios se ven supeditados a la experiencia. ${ }^{7} \mathrm{Y}$ es muy significativo que - a la mínima de cambio - Sempronio espete a Calisto el requisito de la lectura o le muestre esa extrañísima familiaridad que parece tener con los textos de la Antigüedad. En su conversación inicial con Calisto, el criado, a manera de preparativo para el malicioso chiste del ximio, arguye que mujeres

Work: Celestina, Melibea, and the Persuasive Arts", en I. A. Corfis y J. T. Snow, eds., Fernando de Rojas and Celestina: Approaching the Fifth Centenary (Madison: HSMS, 1993), 359-370; E. Palafox, Oralidad, autoridad y retórica en la Tragicomediade Fernando de Rojas, tesis doctoral (1993), Michigan State University.

${ }^{4}$ Russell recoge que en realidad se trata de Bernardo Silvestre de Tours, autor de un texto misógino y confundido durante la Edad Media como obra de San Bernardo, seguramente al que quería interpelar Sempronio (ver su ed. de La Celestina [Madrid: Castalia, 1993], 225, n74).

5 Shipley, "Authority and Experience," 97.

${ }^{6}$ Fernando de Rojas, Celestina. Tragicomedia de Calisto y Melibea, ed. de M. Marciales(Urbana/Chicago: U Illinois P, 1985),II:23 (citaré por esta ed.; se especificará el nombre del editor si se menciona otra edición).

${ }^{7}$ Así sucede, de tono casi igual al de Sempronio, en el Corbacho:"E non pienses en este paso [se refiere a "cómo el que ama aborresce padre e madre, parientes, amigos"] fallarás tú más firmesa que los sabios antyguos fallaron, escpertos en tal sciencia, o locura, mejor dicha. Lee bien cómo fue Adam, Sansón, Davyd, Golyas, Salamón, Virgilio, Aristótiles e otros dignos de memoria en saber e natural juycio..." (ed. de J. González Muela, [Madrid: Castalia, 1970], 55). 
hubo sometidas a acemileros y a animales, y para que lo expuesto quede como adecuado al caso, de nuevo la razón de la lectura: "¿No has leído de Pasife con el toro, de Minerva con el can? (II, 25).

La respuesta de Calisto ("no lo creo, hablillas son") es de corte muy similar a la que Davo, el esclavo de Pánfilo en Andria de Terencio, da a resultas de la peregrina ascendencia que se quiere atribuir a Andria. Cuentos, reacciona Davo, que aunque él no considere verosímiles, "a ellos [a sus amos] les agrada la ficción. ${ }^{8}$ Este soliloquio del esclavo es precisamente descrito por Aelio Donato como "breuis et comica deliberatio." ${ }^{\text {} 9}$ Lo que quiero hacer ver con todo esto es que consideraciones de esta naturaleza no habrían de estar muy a trasmano del primer autor de Celestina. Lo extraño en este caso es que sea el criado el que proponga la literatura y el amo el que la rechace. Esta peculiaridad es muy significativa ya que es cuando menos inusual que un criado dispuesto al engaño tenga siempre a mano lecturas que aconsejar. Pero inusual aquí no significa inconsciente. De todo punto Rojas era conocedor de este espíritu libresco y polémico que gravita sobre el primer acto, y no había de serle para nada ajeno a su vida diaria como estudiante de leyes.

Sempronio y los saberes inútiles.

Así, nada más hacerse con el hilo de la historia, Rojas caracteriza a Sempronio con idéntico perfil pedantesco. De tal manera, y ante la interpelación del enamorado de que la queja aireada alivia en algo la desdicha, Sempronio vuelve sobre sus fueros y su fatuo tonillo de leído: "Lee más adelante; buelve la hoja. Hallarás que dizen que fiar en lo temporal y buscar materia de tristeza, que es igual género de locura" (II, 57-58).Estas palabras se contradicen con las que un poco antes pronunciaba acerca de que los antiguos aconsejaban todo lo contrario: "dizen los sabios que es grande descanso a los afligidos tener con quien puedan sus cuitas llorar, y que la llaga interior más empece" (II, 21). La más leve inconsistencia es inimaginable en alguien mínimamente avezado a las prácticas escolares de la argumentación, a no ser que el espíritu que le guíe sea el de la burla o el escepticismo acerca de la infabilidad del legado hermenéutico. Se podría decir que la casi totalidad de los personajes maneja una terminología escolar que en principio le es ajena por

- ${ }^{8}$ P. Terencio Afro, Comedias, ed. bilingüe de L. Rubio (Barcelona: Alma Mater, 1957) (act. I, esc. III), I:30. Véase E. J. Webber, "The Literary Reputation of Terence and Plautus in Medieval and Renaissance Spain," Hispanic Review 24 (1956), 191-206; Lee A. Sonnino, A Handbook to Sixteenth-Century Rhetoric (Londres, 1968).

${ }^{9}$ Los procedimientos académicos tuvieron muy pronto su paralelo burlesco; véase F. Layna, «La disputa burlesca. Origen y trayectoria», Criticón 64 (1995). 
ubicación social. La relación establecida en la obra entre maestro y discípulo tiene con harta frecuencia una disposición expresiva heredada de las actividades académicas. $^{10}$

El magisterio de Celestina no admite duda, y es ensalzado una y otra vez como auténtica "autoridad", aunque su maestría es consecuencia exclusiva de la experiencia, no del conocimiento de los filósofos de la tradición. Es éste a todas luces uno de los grandes temas del libro, de clara resonancia humanista pues al fin y al cabo no se halla a gran distancia de los ataques a los filósofos de Petrarca, de la polémica de Lorenzo Valla contra los auctores o de la distinción de Leonardo Bruni entre auctoritas y veritas. Ni que decir tiene que esta distinción será determinante en la literatura venidera. ${ }^{11}$ Los dos Lazarillos del 54 y del 55, por poner un ejemplo llamativo, son sucesores directos de este espíritu en que la verdad de la experiencia es irrefutable frente a la verdad de la cultura. De ahí que los consejos librescos de Sempronio o ese constante aire de academicismo del que parece hacer gala puedan ser juzgados como guiños de tinte humorístico.

Este aprovechamiento de materiales de circulación diaria en el ámbito académico ha servido para que en nuestros días Emilio de Miguel insista en sopesar la posibilidad de Rojas como autor también del acto primero. ${ }^{12}$ En este acto inicial son obvios los usos escolares, no sólo el tan extendido de las sentencias y el de la terminología escolástica, sino también un tipo de argumentación pergeñado sobre un molde cercano al del silogismo, que los personajes manejan diestra y falazmente tanto para persuadir al interlocutor como a sí mismos. Estos recursos aparecen de manera sistemática y son, entre otros, expuestos por de Miguel para desempolvar la ya añosa cuestión de la autoría primigenia. De todo esto quizá lo que ahora aquí más interese sea que estos procedimientos no serían ajenos a una posible ironía desplegada desde las primeras líneas de la obra.

La profesora Louise Fothergill-Payne viene dedicando una atención especial a este probable cariz burlesco de Celestina. Centrada sobre aquel consejo de Sempronio y su alusión a Séneca, para mientes en que la futilidad

${ }^{10}$ Shipley, "Authority and Experience."

"Véase Vincenzo de Caprio, "Il contributo del classicismoumanistico alla scienza: auctoritas e ratio nella filología di Lorenzo Valla," en Letteratura e scienzanella cultura italiana. Atti del IX congresodell'associazioneinternazionale per gli studi di lingua $e$ letteratura italiana (Palermo: Manfredi, 1978), 371-384.

${ }^{12}$ E. de Miguel Martínez, 'La Celestina'de Rojas (Madrid: Gredos, 1996), esp. 75-83. 
del conocimiento libresco es algo expresado a lo largo de las páginas de la obra senequista, $y$ en especial en su epístola $88 .{ }^{13}$ Tan proverbial fue la popularidad de Séneca que Petrarca llegó a decir que su "librillo en cada lugar anda entre las manos del bulgo." ${ }^{14}$ Claro está, aquí habría que matizar que Séneca fue también contemplado como un claro ejemplo de la declamatoria affectatio de la que tanto renegaban algunos humanistas. Esta reacción en contra de la obra senequista se originó en la crítica a su estilo que Erasmo realizó en las páginas iniciales de su edición. ${ }^{15}$ A pesar de esta censura, difundida muy rápidamente, la valoración de Erasmo y otros era que si bien Séneca no merecía atención como estilista, sí sin embargo la merecía como moralista. ${ }^{16}$ En cualquier caso Sempronio tan sólo utiliza a Séneca como una autoridad de renombrado prestigio para adornar su sarta de lugares comunes.

Como se ha dicho ya muchas veces, los abusos de la escolástica acentuarán decisivamente la idea de que para un dialéctico la verdad importa bastante menos que la apariencia de su posesión. "Discutiendo en demasía se pierde la verdad" que diría Petrarca. ${ }^{17} \mathrm{Y}$ es precisamente el uso que Rojas hace de Petrarca lo que levantó la sospecha de Fothergill-Payne de que con ello tan sólo se intenta ilustrar la obsesión de los estudiantes de artes liberales con las citas de los poetas laureados. Compara Fothergill-Payne este uso pedantesco del poeta con la acción que va a producirse, y concluye que el efecto resultante es más cómico que dramático. Sin embargo hay que matizar que si hay un punto de partida humorístico de la obra éste no se halla en las páginas prologales, que a fin de cuentas serían las últimas, sino en el primer acto y en las primeras manifestaciones de los personajes. Aun admitiendo por parte de Rojas ironía u ocultación de autoridad, el prólogo recoge una atmósfera de academicismo al margen del alcance cómico y crítico de las palabras de Sempronio.

${ }^{13}$ L. Fothergill-Payne, Senecay 'Celestina' (Cambridge: Cambridge UP, 1988), 96; también su "'Conséjate con Séneca: auctoritas in Celestina and Celestina comentada," en Corfis-Snow, Fernando de Rojas ..., 113-128; véase también J. L. Heller \& R. L. Grismer, "Seneca in the Celestinesque Novel," Hispanic Review 12 (1944), 29-48.

14 Francesco de Petrarca, De los remedios contra próspera y adversa fortuna, trad. de Francisco de Madrid (Valladolid: Diego de Gumiel, 1510), signatura bii vo.

${ }^{15}$ K. A. Blüher, Séneca en España (Madrid: Gredos, 1983), 239ss.

${ }^{16}$ Blüher, Séneca en España, 241.

17 Carta a Tomás de Mesina, contra los viejos dialécticos, en Petrarca, Obras. I. Prosa,ed. Francisco Rico (Madrid: Alfaguara, 1978), 237. 
De la primera aparición del criado sabemos que acaba de terminar el cuidado de los caballos; a su vez, la tarea primera que le encomienda Calisto es que le aderece su cama. Dos labores cuando menos inapropiadas para alguien tan predispuesto a soltar sabiduría a destajo. Al poco, decidido a dejar llorar a Calisto en soledad su amargura, Sempronio ya tiene en mente a aquellos sabios que aconsejan el intercambio de cuitas para tales casos. En resumidas cuentas: del cuidado de las caballerizas se pasa al encarecimiento de la prudencia extraída de la sabiduría. Este salto, de todo punto irregular si no se estima un fin cómico, es sin duda muy parecido al que se produce entre el chiste obsceno del ximio y el ya específico consejo de los auctores. Admítase que es poco serio que tras un chiste alusivo a la supuesta lascivia de la abuela de su amo, le lance aquella lista de eminencias que podían serle de provecho. Pero no sólo eso, sino que el consejo de Sempronio, a todas luces alejado de su incumbencia, parece el resultado de la pregunta que le hace: "¿escocióte el chiste? Pues entonces lee a Séneca y a Aristóteles y a otros muchos que dejaron por escrito constancia de la malignidad de las mujeres." ¿Cómo explicar esta extraña consecuencia si no es mediante un cómico intento de dotar a un mismo personaje con picardía y desparpajo a la par que con una ridícula fatuidad de engolado académico?

Pero es que además Sempronio recurre a la historia, a la filosofía y a la poesía, tres disciplinas que mantienen una muy diversa y distinta relación con la verdad, lo real y lo verosímil. Sin embargo, cita a Salomón, a Séneca, a Aristóteles, a Bernardo (ver n4) y la Biblia. Textos todos que no admitían en la época, al menos en mayoritarios sectores no críticos con las leyes de la Antigüedad, la más mínima duda acerca de su veracidad. Y perfectamente se puede sospechar que no sea gratuita la inclusión de la Biblia. Así, el Texto por excelencia incuestionable también figura en una lista de saberes inútiles ante la supremacía de la experiencia vivida. La reacción subsecuente de Calisto sigue esta misma estela de desconfianza en los saberes: "Di, pues, esse Adan, esse Salomón, esse David, esse Aristóteles, esse Virgilio, essos que dizes, ¿cómo se sometieron a ellas? ¿Soy más que ellos?" (II, 26).

En ningún momento aparecen en la diatriba de Sempronio los nombres de Virgilio o David. Hay quien estima que la inclusión de estos dos nombres pueda ser señal de algún corte en la transmisión manuscrita, o que se trate de una técnica dialogal con la que el autor quiera dar a entender que no ha incluido todos los autores mencionados por Sempronio. ${ }^{18}$ Pudiera ser, pero de igual forma es posible que los nombres de Virgilio y David sean aquí equiparables a un "etcétera", o un Mengano o Futano. Que Calisto no recuerde los nombres alegados por Sempronio pudiera indicar una apatía del

${ }^{18}$ P. E. Russell, ed. de La Celestina,227n84. 
joven ensimismado en su pasión, o bien una manera de atajar su turno de palabra con algo así como "y toda esa consabida morralla de autores que se suele aducir."

Es comprensible, por otro lado, que el recelo de Calisto aflore gracias al insospechado conocimiento del que se jacta su criado. Esto es lo que explica que formule una en apariencia elemental pregunta pero que en sí misma va implícita la duda de la infabilidad de los textos, incluida la Biblia: "¿Y tú qué sabes? ¿Quién te mostró esto?," es la concisa pregunta de Calisto. Tiempo le falta a su criado para con su respuesta dejar bien a las claras que nada de lo expuesto anteriormente tiene la mínima validez, que todo, absolutamente todo, era simple, huero y desatado palabrerío: "¿Quién? Ellas." Esta reacción se sitúa en la misma línea de los bruscos e inesperados cambios de registro que forma parte de un sistema estructural basado en la contradicción. Antes de responder, Sempronio por supuesto no podía dejar de ejercitar su simulado oficio de prudente y ducho consejero: "Miserable cosa es pensar ser maestro el que nunca fue discípulo." Enjundiosa sentencia extraída del De scholarium disciplinadel seudo-Boecio que preludia su reconocimiento de que lo que sabe lo aprendió de su experiencia con las mujeres, no de la lectura de los filósofos y hombres santos que con tanta convicción aconsejaba.

\section{Celestina y la verdad en entredicho.}

Los cambios son considerables: del cuidado de las caballerizas, a la reflexión ponderativa de la más prestigiosa sabiduría; de un chiste obsceno y vejatorio, al vehemente consejo de los auctores; de una sentencia acerca de la naturaleza del maestro, a la confesión de que sólo la experiencia es la que proporciona el don del conocimiento. ¿Cómo enfrentarnos a estos cambios de registro si no es mediante un molde cómico encaminado a la mofa de los usos y maneras de los sistemas de enseñanza y adquisición del conocimiento? Aquí es cuando se puede ver nítidamente ese enfrentamiento entre sabiduría y experiencia del que hablábamos, y todavía más cuando tras su sincero reconocimiento vemos que Sempronio aconseja los servicios de la vieja y experta Celestina. Pero antes de que ésta ponga en práctica sus habilidades de tercera, Calisto procede a una apasionada descripción de Melibea, tras la cual Sempronio insiste en que aunque todo lo expuesto por su joven amo fuera cierto: "ella es imperfecta, por el cual defeto dessea y apetece a ti y a otro menor que tú. ¿No has leído el Filósofo do dize: 'assí como la materia apetece a la forma, assí la muger al varón?'"

Es cómica esta apropiación de Aristóteles para una falacia nada sutil, puesto que el que irrefrenable se consume de deseo es Calisto, no Melibea. No se puede evitar que llegado a este punto la imaginación se vaya a las risas de los escolares que asistieran a la lectura o representación de la obra, y acaso a 
la preocupación de sus maestros. Porque después de tanto filósofo aconsejado casi a bocajarro, el criado concluye su actuación de perspicaz consejero recomendando los servicios de una vieja "hechizera, astuta, sagaz, " por cuya autoridad "passan de cinco mil virgos los que se an hecho y desecho" (II, 30). En dos palabras, la vieja Celestina es la más recomendable autoridad para buscar el adecuado remedio al ansia erótica de Calisto.

No cabe duda de que aquí la experiencia figura en radical oposición a la doctrina y el tratado. Esto se acerca al concepto renacentista de la experiencia como proceso vivo y dinámico de conocimiento, origen y motor de la Historia. Bien es cierto que durante toda la Edad Media se produce un cierto hastío de lo trascendente, apoyado y fomentado desde ciertas órdenes religiosas. Los franciscanos, por ejemplo, rechazaban el sistema cognoscitivo aristotélico basado en una relación estática e intemporal con un Entendimiento supremo y metahumano. La experiencia suponía un concepto de hombre en proceso alejado del Ser Absoluto de la Metafísica. Esta conciencia de crisis es la que late en las primeras páginas de Celestina. Conciencia crítica reflejada incluso en un lenguaje no sujeto a la relación exigida por el concepto de congruitas entre estilo y materia tratada. ${ }^{19}$

La reacción imprevista, el comentario inesperado o los cambios de registro lingüístico y moral son algunas de las características de la naturaleza del chiste. Estos cambios o saltos son abundantísimos en el primer acto de Celestina, expuestos directamente o mediante contradicciones, ambigüedades o falacias. Se ha querido ver en el parlamento de Sempronio contra las mujeres un tipo de indignatio, estrategia retórica estipulada para indisponer al público con la causa de la parte contraria. ${ }^{20} \mathrm{Al}$ margen de si existe o no esa figura retórica, lo reseñable es que la reacción que provoca en Calisto es la inesperada: "¿Ves?Mientras más me dizes y más inconvenientes me pones, más la quiero" (II, 27). Entraría también dentro de esta categoría de lo cómicoinesperado el maestro que carece de lo que advierte a sus discípulos. Esto es lo que le sucede al Sempronio que se inventa a sí mismo como hombre experto en mujeres, y al que podemos ver engañado por su amante Areusa con el ardid de la evidencia, es decir, manifestando ostensiblemente que las sospechas de Sempronio son ciertas a fin de provocar el efecto contrario. ¿Dónde quedan tras el engaño aquellas autoridades que manejaba con una suficiencia pasmosa?

${ }^{19}$ Paolo Cherchi, "Onomástica celestinesca y la tragedia del saber inútil", en R. Beltrán \& J. L. Canet, eds., Cinco siglos de 'Celestina': Aportaciones interpretativas (València: Univ. de València, 1997), 89.

${ }^{20}$ Fothergill-Payne, "Conséjate con Séneca," 117. 
Desde la persona encargada de localizar y compilar al auctor, a la consecuencia provocada por el consejo magistral, todo aparece fuera del contexto apropiado, parodia al fin del prestigio de los usos escolásticos. La reacción no podía ser otra sino la de la risa. Así nos lo hace saber fray Diego de Estella cuando recomendaba el uso de concordancias bíblicas a la hora de la búsqueda de autoridades por parte del predicador:

Y procure sobre todo el predicador de no traer las autoridades torcidas y, como dicen, por los cabellos, sino en el propio sentido literal, que es gran falta en el predicador del Evangelio que traiga la autoridad a un propósito, estando ella en la Escritura puesta a otro.Y debe mucho mirar en esto, porque no dé lugar de risa a los hombres doctos y sabios que le estuvieren oyendo. ${ }^{21}$

Pero hemos de fijarnos en algo de vital importancia y que, aunque envuelto en ropajes de humor, tiene el viso de preocupación y de serio dilema. Celestina se las tiene que ver con un receloso Pármeno. Quedan ya atrás los vanos intentos de Sempronio de convencer a su amo. Diría que este Sempronio consejero de la sabiduría es el arranque cómico de un problema que se quiere ofrecer como de envergadura. Ahora Celestina tiene que persuadir, convencer, reducir a Pármeno a sus intereses. Y para ello utiliza de nuevo el nombre de Séneca, el de Virgilio, el del Sabio que respalda y asegura la fiabilidad de lo nombrado. Celestina le insta a que abandone los ímpetus de la juventud, algo que le es por naturaleza imposible, y que se torne a la razón, como si ésta fuera algo privativo de la vejez.

Recuérdese lo habitual que era asimilar 'razón' a 'verdad absoluta'. Y hay quien sugiere que, contrariamente a lo que dice Quintiliano, en Celestina se usa la retórica para mostrar que no siempre es un proceso honorable que lleva a ilustrar la verdad. ${ }^{22}$ No es, pues, ajena a conflictos relativos a la certeza la labor de tergiversación llevada a cabo por Celestina, necesitada por otro lado del prestigio del auctor, de su presencia a modo de juez que no admite apelación alguna. Sin embargo aquí se trata de convencer con fines específicos y personales. Hay un momento crucial en que Pármeno, ablandado ya por la exposición demostrativa de Celestina, formula con precisión la trampa retórica en la que ha caído, pero sin ser consciente de que él es la víctima. De nuevo la evidencia delante de los ojos para conseguir la negación de su existencia.

${ }^{21}$ Fray Diego de Estella, Modode predicar y Modus Concionandi, ed. de P. Sagüés Azcona (Madrid: CSIC, 1951), II:70-71.

${ }^{22}$ E. Morgan, "Rhetorical Technique," 7 [ver n3]. 
Dice Pármeno: "No querría, madre, me combidasses a consejo con amonestación de deleite, como hizieron los que, careciendo de razonable fundamento, opinando hizieron setas embueltas en dulce veneno para captar $\mathrm{y}$ tomar las voluntades de los flacos, y con polvos de sabroso afeto cegaron los ojos de la razón" (II, 51).

¿Quiénes fueron aquellos que, sin el amparo de la razón, moldearon la voluntad de los inocentes, como ahora cree un astuto Pármeno que Celestina intenta hacer con él? ¿Hay en los actos posteriores un específico desarrollo de lo ahora planteado por el personaje? Es obvio que en este primero su desconfianza no puede ser aislada de esa conflictiva relación entre conocimiento y'experiencia, de aquel descrédito de la verdad como centro axial del conocimiento.

A su vez, la reacción de la vieja tercera es la de una experimentada maestra en las mañas del embaucamiento y la mixtificación dialéctica:

¿Qué es razón, loco? ¿Qué es afeto, asnillo? La discreción, que no tienes, lo determina; y de la discreción mayor es la prudencia; y la prudencia no puede ser sin esperimento; y la esperiencia no puede ser más que en los viejos; y los ancianos somos llamados padres; y los buenos padres bien aconsejan a sus hijos, y especial yo a ti, cuya vida y onra más que la mía desseo. ¿Y cuándo me pagarás tú esto? Nunca, pues a los padres y a los maestros no puede ser hecho servicio igualmente. (II, 51)

Queda claro aquí que la experiencia es la cualidad más estimable, y que el consejo más sabio es el propuesto por la persona curtida por el tiempo y los avatares de la vida. Celestina renuncia ahora a las autoridades para introducir en su serie argumentativa un elemento falaz que atraerá la voluntad de Pármeno hacia sus intereses. Como se ha señalado, que la vieja alcahueta se reconozca dentro de la categoría de "buenos padres" es una intromisión espuria de algo que no se demostrará en ningún momento a lo largo del libro. ${ }^{23} \mathrm{La}$ extensa experiencia de Celestina no abriga nada que se halle alejado de su conveniencia más inmediata. Su victoria es el triunfo de la impostura, formulada en aquel impresionante "a la verdad eres reducido" con que termina el acto y la oposición de Pármeno. Diríase que para Celestina la verdad es una cuestión de lenguaje. Este es el gran debate formulado en los inicios de la obra:

${ }^{23}$ E. de Miguel Martínez, La "Celestina"de Rojas, pág. 81. Véase I. Mitxelena, Algunas observaciones acerca del comienzo de 'La Celestina' (Bilbao: Univ. del País Vasco, 1996), 217. 
la expresión de que detrás de los procesos de conocimiento la verdad es susceptible de perder su carácter de inmutabilidad. En esta línea, la misma verdad cristiana correría el riesgo de la manipulación. El problema, como puede comprobarse, no es de poca monta.

El escepticismo y la verdad imposible.

Podría ser el epítome de la escepsis: «Todo lo que no pueda ser verificado por la experiencia es mera especulación filosófica.» De dos diferentes escuelas surgió el pensamiento escéptico: la desarrollada en la Academia platónica (s. III a.C.), mantenedora de que no es posible conocimiento alguno, y la Pirrónica, fundada en Alejandría por Pirrón de Elis (c.360-225a. C.), y que afirma que la evidencia es insuficiente para determinar si es posible algún conocimiento, por lo cual sólo queda suspender el juicio acerca de todo lo relativo a cuestiones del conocimiento. Lo único, pues, a nuestro alcance es expresar la perplejidad ante la naturaleza contradictoria de todas las percepciones e ideas. Por otra parte, los pirrónicos se opusieron tanto a los dogmáticos (aquellos que aseguraban conocer alguna verdad acerca de la naturaleza de las cosas) como a los académicos (por su rotunda seguridad al afirmar que nada puede conocerse). La obligada suspensión del juicio traía consigo la ataraxia, conducente a la felicidad. A grandes rasgos, en esto consistía el escepticismo.

Los únicos textos conservados del movimiento pirrónico son los de Sexto Empírico. ${ }^{24}$ Sus obras principales son una especie de antienciclopedia contra toda clase de ciencia o conocimiento, desde la lógica a la gramática, pasando por la música. Un sobrino de Giovanni Pico della Mirandola, Gianfrancesco, escribirá su Examen Vanitatis doctrinaegentium (1520), ataque a la filosofía aristotélica elaborado al amparo de la obra de Sexto, aunque ya tendrá el cariz fideísta, alejado del academicismo o pirronismo originales, que definirá el escepticismo del siglo XVI: es decir, la única verdad posible es la que emana de las Sagradas Escrituras. ${ }^{25} \mathrm{Si}$ bien se acepta que es en este siglo

${ }^{24}$ Sextus Empiricus, ed. bilingüe griego-inglésde R. G. Bury, Cambridge: Harvard UP, 1976. 4 vols. Hay traducciones españolas, la legendaria de Lucio Gil Fagoaga, Doctrinal del escéptico(Madrid: Reus, 1926), y recientemente, Esbozos pirrónicos, trad. de Antonio Gallego Cao y Teresa Muñoz Diego (Madrid: Gredos, 1993) e Hipotiposis pirrónicas, trad. y ed. de R. Sartorio Manlini (Madrid: Akal, 1996).

${ }^{25}$ Sobre estas cuestiones es fundamental C. B. Schmitt, "The Rediscovery of Ancient Skepticism in Modern Times," en M. Burnyeat, The Skeptical Tradition (Berkeley: U California P, 1983), 225-52; En España hay varios códices griegos de la obra de Sexto de finales del XV y primera mitad del XVI en la biblioteca del Escorial. Hay un manuscrito latino de hacia 1400 en la Biblioteca Nacional de Madrid (Ms. 
cuando el escepticismo alcanza su mayor repercusión gracias a la traducciones latinas, Popkin cree que antes

hay ciertas tendencias de un motif escéptico, sobre todo entre los teólogos antirracionales, judíos, mahometanos y cristianos. Este movimiento teológico, que en Occidente culminó en la obra de Nicolás de Cusa en el siglo XV, se valió de muchos de los argumentos escépticos para socavar la confianza en el enfoque racional a la verdad y el conocimiento religiosos. ${ }^{26}$

En apoyo a lo dicho por Popkin, el estado de ataraxia pirrónica no ha de ser ajeno a la negación de la filosofía racional del esoterismo mistérico de Nicolás de Cusa, prolegómeno del fideísmo de Pico de la Mirándola y sustento intelectual de la humildad evangélica propuesta por ciertas órdenes mendicantes. ${ }^{27}$ Recuérdese que San Agustín experimentó un periodo de cristianismo platónico que de alguna manera favoreció cierto escepticismo en la capacidad cognoscitiva del hombre. Pero es que además tenemos el testimonio de Siger de Brabant, averroísta del siglo XIII que en su tratado acerca de lo imposible contestó a alguien, del que desconocemos su identidad, por considerarle excesivamente extremo en su escepticismo. Al parecer este anónimo autor planteaba la posibilidad de que el hombre estuviera completamente equivocado en sus juicios. ${ }^{28}$

10112). Fue durante mucho tiempo erróneamente catalogado como un fragmento de Aulo Gelio por J. Millas Vallicrosa. El error fue descubierto por Paul O. Kristeller (Iter Italicum [Leiden: Brill, 1989], IV: 567b-568a).En el lomo recibe el nombre de Pirhoniae Tractatus, y en el primer folio, con letra posterior a la del manuscrito Liber pirroniay in forma comuni. Para el impacto del escepticismo sobre la fe, D. C. Allen, Doubt's Boundless Sea (Baltimore, 1964) y Terence Penelhum, God and Skepticism.A Study in Skepticismand Fideism (Dordrecht: Reidel 1983); del mismo "Skepticism and Fideism," en M. Burnyeat, The SkepticalTradition, 287-318.

${ }^{26}$ Richard H. Popkin, La historia del escepticismo desde Erasmo hasta Spinoza (México: Fondo de Cultura Económica, 1983), 14-15 [trad. de The History of Scepticism from Erasmus to Spinoza, (Berkeley: U California P, 1979)].

27 Véase Domingo Ynduráin, Humanismo y Renacimiento en España (Madrid: Cátedra, 1994), 247-257.

${ }^{28}$ M. Beuchot, "Some Traces of the Presence of Scepticism in Medieval Thought," en Richard H. Popkin, ed., Scepticismin the History of Philosophy:a Pan-American Dialogue (Dordrecht: Kluwer, 1996), 37-43. También de Beuchot "Escepticismo en la Edad Media: el caso de Nicolás de Autrecourt," Revista Latinoamericanade Filosofía 15 
Volviendo al pirronismo y respecto a la dimensión ética de la filosofía, Sexto Empírico niega la existencia de una realidad que contenga en sí lo bueno o lo malo. Según él, desde el momento en que los estoicos, los peripatéticos, todos los dogmáticos, no definen la esencia del Bien sino accidentes que se dan en él, es algo completamente imposible hacerse una idea de en qué consiste el Bien. Lo mismo, claro, sostiene de la existencia del concepto de maldad. ${ }^{29}$

Curiosamente una de las formas de divulgación del escepticismo fueron las muchas reacciones que en su contra se escribieron. Así, en la primera mitad del siglo XVI, Guy de Brués será uno de los que se enfrenten al pirronismo en sus Dialogues. Siguiendo esa suspensión del juicio aconsejada por Sexto en lo relativo a lo que es bueno y malo, Aubert, el portavoz del escepticismo de los cuatro interlocutores del diálogo, afirmará que la virtud sólo es una palabra inventada por nuestra imaginación, y lo que una república ha tenido por honesto en otra se ha considerado deshonesto:

¡O Dios, si fuésemos sensatos te rogaríamos que nos permitieses volver a nuestra primera inocencia, exorcizando de nosotros este desgraciado afán de querer separar lo honesto de lo deshonesto, el vicio de la virtud, y querer con demasiada curiosidad rebuscarlo todo!" (Dialogues, 153, 186). ${ }^{30}$

Este escepticismo no sonaría desconocido en la España de Rojas, pues a buen seguro se vería arropado por una atmósfera intelectual que merece una atención especial por parte de la crítica. En efecto, bien se hable de averroísmo, de aristotelismo heterodoxo o de racionalismo radical, bien encaminemos nuestras miras de estudio hacia vías de penetración judaicas o

(Buenos Aires, 1989),307-319. Véase Ch. Jourdain, "Sextus Empiricus et la philosophie scolastique," en ExcursionsHistoriques et Philosophiques a travers le Moyen Âge (Paris: Firmin-Didot, 1888), 201-217 y W. Cavini, "Appunti sulla prima diffusione in Occidente delle opere di Sesto Empirico," Medioevo. Rivista di Storia della Filosofia Medievale 3 (1977), 1-20.

${ }^{29}$ Sexto Empírico, Esbozospirrónicos,292-316.

${ }^{30}$ Traducción extraída del libro de J. A. Fernández Santamaría, Juan Luis Vives. Escepticismo y prudenciaen el Renacimiento (Salamanca: Universidad, 1990), 52n37. 
latinas, ${ }^{31}$ desde luego en la época no habría de pasar desapercibida cualquier actitud de descreimiento y de naturaleza escéptica. No han de faltar muchos años para que el portugués Francisco Sánchez, que se define a sí mismo como heredero del escepticismo pirrónico y académico, ansíe un destello de verdad con el solo rechazo de las antiguas autoridades. ${ }^{32}$

Llegados a este punto lo que aquí atañe es comprobar cuál es la relación entre el primer acto de Celestinay lo expuesto en líneas precedentes. Las cuestiones que habría que dilucidar, más o menos, son las que siguen:

$\square$ ¿No podría ser de influencia escéptica, o semejante, el pulso que late en aquellas páginas iniciales de la obra?

$\square$ ¿No es el "a la verdad eres reducido" de la vieja tercera un trastrueque de vicios y virtudes resultante de una verdad accidental, susceptible de mil y un cambios en su contenido conceptual?

$\square$ ¿No merodea por allí esta indiscriminada amalgama de lo honesto y lo deshonesto, de lo bueno y lo malo?

$\square$ ¿No es consecuente con esta actitud estimar el lenguaje como una convención incapaz de definir la realidad, sujeta a un sinfín de contradicciones, tal y como sucede desde las primeras páginas en Celestina? ${ }^{33}$

Sea como sea, mi intención únicamente es dejar formuladas estas preguntas al mismo tiempo que una duda: la probable discontinuidad en Celestina entre una inicial preocupación filosófica y el desarrollo posterior, incluido el desenlace. Hoy día es difícil encontrar a alguien que no acepte que Celestina sea un texto colmado de ambigüedades expuestas a múltiple

31 Véanse F. Márquez Villanueva, "'Nasçer e morir como bestias' (criptojudaísmo y criptoaverroísmo)," en F. Díaz Esteban, ed., Los judaizantes en Europay la literatura castellana del Siglode Oro (Madrid: Letrúmero, 1994), 273-293;F. Márquez Villanueva, "El caso del averroísmo popular español (hacia la Celestina),"en R. Beltrán \& J. L. Canet, eds., Cinco siglos, 121-132; John Edwards, Religion and Society in Spain (Brookfield: Variorum, 1996); F.Rico, "'Por aver mantenencia': El aristotelismo heterodoxo en el Libro de Buen amor," Libro homenaje a José Antonio Maravall (Madrid: Centro de Investigaciones Sociológicas, 1986), 271-297.

${ }^{32}$ Francisco Sánchez, Quod nihil scitur, Lugduni: Apud Ant. Gryphium, 1581.

33 Véase para un asunto similar, pero relativo al libertinismo erudito o esprit fort en Celestina, Ottavio Di Camilo, "Ética humanística y libertinaje," en Humanismo y Literatura en tiempos de Juan del Encina, (Salamanca: Universidad, 1998), 69-82. 
interpretación. ${ }^{34}$ Consciente de ello, quisiera insistir en la presencia de una especie de disonancia conceptual entre el primero y los restantes actos. Porque en aquellos inicios la opción experimental quedaba como única alternativa, y la verdad se supeditaba a los rigores de los fenómenos circunstanciales; allí también quedaba una arreligiosidad sorprendente tras la inclusión de la Biblia dentro del ámbito de los saberes inútiles, y, en definitiva, detrás de todo, en aquel capítulo se extendía la sombra del conflicto que provocaba el rechazo de la Antigüedad causado por el carácter inane de la doctrina.

$Y$ todo ello no era sino el reflejo del contraste entre sabiduría y experiencia. ¿Podríamos decir que prosigue expresamente este contraste, que se desarrolla y culmina en la continuación de la obra? Se podrá aducir que se trata del conflicto original incitador de la acción, pero es un dilema de honda y crucial repercusión para que sus hilos temáticos no se extiendan y determinen la naturaleza de los acontecimientos.

\section{El alcance de la magia.}

Dentro de este desacuerdo entre el arranque y el desarrollo posterior se podría de igual forma tratar la función que ejerce en la obra la hechicería. Este es terreno trillado que a pesar de todo sigue aceptando mucha atención, y acaso en especial en lo que respecta al famoso todo era burla y mentira de Pármeno. Al poco de conocer al nuevo criado, asistimos a una pormenorizada descripción del laboratorio de Celestina. Es este aspecto de la minuciosidad el que provoca que su final sea un corte especialmente brusco: Pármeno concluye su aviso a Calisto de las artes malsanas de Celestina con el "y todo era burla y mentira." La pregunta, pues, es la consabida: ¿cómo concordar las palabras de Pármeno con el determinismo funcional que la magia jugará en el desarrollo de los acontecimientos?

Y hay un problema de fondo que ha enturbiado un tanto toda esta cuestión y que hay que encarar desde un primer momento: la presencia de la magia no tiene por qué suponer exclusión de habilidades persuasivas de la vieja ajenas a su competencia como hechicera. Ya vimos con qué facilidad Celestina se merendaba a un Pármeno nada propicio a su persona y maneras. Ahora bien, esta conversión del criado mediante una hábil estrategia argumentativa sucede en los instantes primeros de la obra, al igual que aquella esporádica rúbrica de la mentira y la burla expresada por Pármeno. En resumen, la función que la magia vaya a jugar no se desprende de estos momentos iniciales.

${ }^{34}$ Tal vez un caso sea el de Vicente Cantarino, "Didactismo y moralidad de La Celestina," en M. Criado del Val, dir., 'La Celestina'y su contorno social.Actas del I Congreso Internacional sobre'La Celestina' (Barcelona: Borrás, 1977), 103-109. 
Por tanto, y según la dinámica de lo que hasta ahora se ha visto, ¿qué impediría contemplar estas palabras de Pármeno como del mismo orden que las utilizadas por Sempronio para finalizar su serie de autores y reconocer que la experiencia era su único método de conocimiento? La frase "y todo era burla y mentira" cumpliría, pues, la misma función que "¿Quién? Ellas." Es muy significativo que Juan Sedeño, en su versión en coplas reales de la Tragicomedia, decidiera cambiar la frase de Pármeno por "y era todo vanidad." 35

Durante un tiempo Russell fue uno de los mayores defensores de la magia entendida como elemento orgánico de vital importancia en el entramado y desarrollo de la obra. ${ }^{36}$ Esto parece que no admite duda, si bien Bataillon, ajustándose a las palabras de Pármeno, suponía que para el primer autor no eran relevantes los poderes mágicos de Celestina; por el contrario Rojas otorgaba, según Bataillon, una gran eficacia a la hechicería de Celestina. En principio no supone ninguna inconsistencia basarse en las palabras de Pármeno, sobre todo cuando tras ellas su amo decide cambiar de registro en la conversación y volver a su apremio por dar fin a su deseo.

La reacción es la misma que aquella de "ves, cuanto más me dices, Sempronio, más la quiero." Russell cree que detrás de las palabras de Pármeno se halla la teoría tradicional acerca de la hechicería, y que.la palabra "burla" hace referencia a que en realidad era el diablo el que se burlaba de las hechiceras. Por lo tanto considera posible que el propósito del comentario de Pármeno sea recordar al lector la doctrina ortodoxa, "según la cual la víctima de la burla era tanto la misma Celestina como sus clientes" (Russell, edición, 73).

Nada impide que así sea, no obstante lo que hasta ahora ha sucedido no parece muy en consonancia con esta posibilidad, sí quizá con los acontecimientos venideros. Se pregunta Russell si las palabras de Pármeno no serían "una observación añadida como precaución, tal vez por el mismo Rojas, con el objeto de evitar que se le pudiese acusar de haber enumerado, sin condenar su uso, muchos de los instrumentos de que se valían las hechiceras en la Castilla de su día, y largo tiempo después, para sus propósitos malignos" (Russell ed., 73; Temas, 257).

\footnotetext{
${ }^{35}$ Ejemplar incompleto de la Biblioteca Nacional de Madrid (R/9683), signatura Bi $v^{0}$.

${ }^{36}$ P. E. Russell, "La magia, tema integral de La Celestina," en su Temas de 'La Celestina' (Barcelona: Ariel, 1978), 243-276y la introducción a su ed. de La Celestina (Madrid: Castalia, 1993), 67-76.
} 
Que se deban a una redacción posterior y tal vez debidas a la mano de Rojas es algo que, por el momento, no admite mayor reflexión por exceso de incertidumbre. Pudiera ser, pero desde luego nada de lo previo a las palabras de Pármeno se ajusta a esa necesidad de ponderar usos derivados de la práctica del poder, antes bien todo lo contrario en un mundo en que cualquier dictamen depende de la experiencia personal. Russell insiste en una tesis no muy en la línea de esta dialéctica establecida entre sabiduría y experiencia de la que venimos hablando. Considera que es "la relación de Celestina con los poderes ocultos lo que explicaba las dotes intuitivas excepcionales, los conocimientos eruditos y el poder suasorio fenomenal que permitían a esta mujer ineducada de las capas bajas embaucar con sus argumentos incluso a las personas educadas con quien entraba en contacto, facilitando así su tarea de diseminar el mal dentro de la sociedad" (Russell, ed., 75).

Pero si así fuera, ¿qué haríamos con aquel Sempronio tan capaz de manejar textos y autores con una suficiencia pasmosa?; ¿y con el esmeradísimo retoricismo utilizado por Calisto para describir a Melibea? Precisamente la condición ineducada de Sempronio o de Celestina aparece bajo un énfasis revelador, nada neutro, y no se olvide que en menos de un acto, lo que supone una evidente premura por entrar en materia, por situar realidades en posiciones dispares, por ensalzar unas en detrimento de otras.

No se vea en lo precedente una crítica a la lectura de Russell, sino una forma de evidenciar que hay una falta de concordancia entre el primer acto y el resto de la Tragicomedia que provoca una sensación de líneas argumentativas no continuadas. Razones no le faltan a Russell para estimar la magia como una fuerza determinante ${ }^{37}$ ¿Cómo no habría de ser así cuando vemos que la invocación a Plutón la realiza la vieja hechicera en la más completa soledad? A partir de esta circunstancia la función de la magia adquiere un valor fundamental, pero su funcionalidad no es algo expreso en los inicios de la obra, aquellos donde todo conocimiento, incluido el mágico, soporta sobre sí el peso del escepticismo.

\section{PRÓlOGO Y CARTA A UN SU AMIGO.}

Tanto uno como otra han quedado para la crítica como los lugares donde Rojas elude todo lo que signifique claridad y precisión. De patrones

${ }^{37}$ Véase para el propósito P. Botta, "La magia en La Celestina," Dicenda 12 (1994), 37-67; A. Vian Herrero, "El pensamiento mágico en Celestina, 'instrumento de lid o contienda'," Celestinesca 14.2 (1990), 41-91; A. Vian Herrero, "Transformaciones del pensamiento mágico: el conjuro amatorio en 'La Celestina' y en su linaje literario," en Beltrán/Canet, eds., Cinco siglos, 209-238 (esp. 210-211n5). 
literarios bien conocidos, hasta tal punto prólogo y carta recogen afirmaciones insostenibles de por sí, que hablar de impenetrabilidad o hermetismo supone $\mathrm{o}$ una renuncia a su estudio o una ingente marea de interpretaciones. $\mathrm{Y}$ a veces da la impresión que ambas soluciones tienen un algo de derrota infligida por Rojas desde la lejanía de los siglos.

Si se interpreta la inconsistencia del prólogo y la carta con el fin de localizar elementos de unión o desunión con la obra entera, las posibles conclusiones en parte dependerán de nuestra interpretación de los prolegómenos de la obra. Si creemos lo que nos dice sobre su hallazgo del primer autor, y no así sin embargo lo referido al escaso tiempo empleado en la continuación, habrá, pues, que decidirse sobre el criterio que rija nuestra credibilidad. Esta duda, como se sabe, pertenece a la tradición de la crítica celestinesca, pero aun admitiendo la presencia en estas partes extradramáticas de ironía, de carácter polisémico, de significado recóndito, o incluso de maestría en técnicas del fingimiento, aun así no se sacude uno de encima la sensación de que se deben a una mentalidad distinta a la que compuso el primer acto.

\section{PRÓlogo.}

Suele aceptarse que es Chrétien de Troyes el primero que en un prólogo, el de Erec y Enid, manifiesta una actitud de distanciada crítica respecto a su fuente. Y en efecto, tras hacerlo así, de inmediato pasa Chrétien a alabar su propia función de autor, de absoluta vigencia, según su parecer, durante todo el tiempo que perviva la cristiandad. Esto evidentemente implica un cambio sustancial de actitud, el que va de la pleitesía a las leyes de la Antigüedad al interés por la recepción futura del texto. Se dice que es a partir de este prólogo cuando el reconocimiento de la autoría se refugia en una serie de estratagemas. Así, Jean de Meun, Chaucer o Boccaccio, tres ejemplos muy citados, se reconocerán en un mero papel de compiladores, con la consiguiente e irónica posición de rechazo de cualquier tipo de responsabilidad que ataña al contenido de sus libros. ${ }^{38}$ Actitud muy distinta, aunque parezca lo contrario, a la de los auténticos recopiladores de la sabiduría. El grueso de la escritura medieval fue provista por las glosas y comentarios a los autores de la Antigüedad, los flox auctorum, cuyos compiladores tampoco deseaban hacerse

${ }^{38}$ Deborah N. Losse, "From Auctor to Auteur. Authorization and Appropriation in the Renaissance," Medievalia et Humanistica 16 (1988), 153-163. 
cargo de la verdad o falsedad de sus fuentes. ${ }^{39}$

La ironía era lo que diferenciaba a Boccaccio de éstos: es una argucia demasiado evidente culpar a las mujeres de la posible pobreza de su técnica narrativa. Por otro lado, la escritura dejaba peligrosamente al lector la interpretación de los textos. De ahí que los prólogos y epílogos, en un claro intento de reducir ambigüedad (aunque a veces de aumentarla), asignasen sentidos últimos a las obras. ${ }^{40}$

Cuando Rojas escribe su prólogo a Celestina,parece que le preocupa sobremanera que se le considere si no partícipe, al menos deudor de la idea medieval de la composición en curso. Porque son muchas las veces en que vuelve sobre el hecho de que la obra está entretejida de sentencias y dichos. Tampoco se halla muy lejos de este anhelo la alusión a las punturas de los impresores. ¿Deseo de adscribirse a una categoría cercana a la de compilador? Difícilmente, puesto que Rojas defiende su proceder literario y la naturaleza singular de su obra. Lo que está a la vista es que intenta una solución de raigambre para su propuesta de tragicomedia.

Con el Praefatio del De remediis de Petrarca como plantilla, inicia la primera parte de su prólogo con el desarrollo de una sentencia que supone que el devenir de todas las cosas está regido por la ley universal de los opuestos. La discordia y la concordia son los elementos que definen el entramado del mundo. La ley, nos dice, es de validez universal, bajo cuya égida cualquier aspecto de disparidad requiere una explicación. Como se ve, es un conocido lugar común de todos los tiempos: "Este mundo es máquinas y trazas contrarias unas de otras", como diría Don Quijote (II Parte, c. 29).

Ahora bien, llegado a este punto la duda es inevitable: ¿cuál es la correspondencia entre esta idea, de categoría y aplicación universal, y el espíritu de escepticismo bajo el cual se proyectaba el primer acto? ¿O es que se ajusta el prólogo a la totalidad de la obra sin tener presente desacuerdos

${ }^{39}$ A. J. Minnis, MedievalTheory of Authorship: Scholastic Literary Attitudes in the Later Middle Ages (London: Scolar Press, 1984). También de Minnis, "Late-Medieval Discussions of Compilatio and the Role of the Compilator, "Beiträge zur Geschichteder Deutschen Sprache und Literatur 101 (1979), 385-421. Desde una óptica postestructuralista, J. M. Gellrich, The Idea of the Book in the Middle Ages: Language, Theory, Mythology and Fiction (Ithaca: Cornell UP, 1985). Para cuestiones más generales, R. Weimann, Authority and Representation in Early Modern Discourse (Baltimore/London: Johns Hopkins UP, 1996).

40 Véase Eloísa Palafox, Oralidad, autoridad y retórica en la Tragicomedia de Calisto y Melibea de Fernando de Rojas, 111ss [ver n3]. 
aislados? Está fuera de toda duda que Rojas busca el amparo del prestigio, aun en el caso de que detrás haya voluntad de humor; pero Petrarca, aquel que decía que la verdad se pierde por debate en demasía, no es un autor que se compenetre con las definiciones iniciales de los personajes. Lo que hará Petrarca será criticar la frecuente identificación entre verdad y obra de Aristóteles cuando, según él, existe una idea de verdad, la que deriva de la Biblia, que no admite matización ni pesquisa alguna.

En el De Remediis llega a afirmar, parafraseando a Lactancio, que tanta es la fuerça de la verdad "que muchas vezes trahe a sí las lenguas aun de los enemigos. ${ }^{41}$ ¿Cómo, pues, comulgar estas palabras con aquellas de "a la verdad eres reduzido" con que cínicamente Celestina concluía su disputa con Pármeno? ¿Habría que hablar de despistes, de inconsistencia, de falta de rigor argumentativo? Raro sería que a un estudiante de leyes en Salamanca se le pasara por alto cualquier tipo de incoherencia, aún más la suya.

Durante la Edad Media el acopio de saberes era una exigencia de la memoria, y el acceso de la gran mayoría de los estudiantes a la herencia del pasado se produjo gracias a los extractos de los escoliastas y glosadores. Rojas utilizó estas recopilaciones y participó de un sistema docente que hacía de la sentencia un proceso en curso del conocimiento. En la Carta a su amigo Rojas se presenta tan entusiasmado con la lectura del primer acto, que "tanta más necesidad me ponía de releerlo y tanto más me agradava y en su processo nuevas sentencias sentía" (II, 3). Y en el prólogo recalcará la misma idea, nada más que ahora en relación con el prototipo de lector:

Unos les roen los uessos que no tienen virtud, que es la istoria toda junta, no aprovechándose de las particularidades, haziéndola cuento de camino; otros pican los donaires y refranes comunes, loándolos con toda atención, dexando pasar por alto lo que haze más al caso y utilidad suya. Pero aquellos para cuyo verdadero plazer es todo, desechan el cuento de la istoria para contar, coligen la suma para su provecho, ríen lo donoso, las sentencias y dichos guardan en su memoria para trasponer en lugares convenibles a sus actos y propósitos" (II, 12).

La idea es de clara estirpe medieval. Enrique de Villena, por ejemplo, tras citar de corrido a treinta y ocho autores, concluye que:

${ }^{41}$ Petrarca, De Remediis utriusquefortunae, I, 13. Utilizo la traducción de Francisco de Madrid (Valladolid: Diego de Gumiel, 1510), signatura Cv recto. Véase D. Ynduráin, Humanismo y Renacimiento en España,134-146. 
E cada uno dellos paresçía ofreçerse ministrar actoridades quantas menester oviese, a decoraçión e conplimiento del fazedero tractado, lo que non dudo fazer pudieran. E por non menospreçiar alguno dellos, acordé de todos acorrerme, tomando de sus dichos lo que al mío fiziese propósito, situando en aquellos lugares donde más lunbre e testimonio fulgiesen; con todo esto, non obmitendo las actoridades bíblicas e legales onde último esperava refugio. ${ }^{42}$

Estamos hablando, junto con Villena, de "las sentencias y dichos" de Bernardo, de Séneca, de Aristóteles, en fin, de todos aquellos de los que Sempronio nos había dejado bastante claro que poco o ningún servicio se podía extraer. ¿Tendremos que hablar de una actitud irónica de Rojas también para aquellas palabras? Poca ironía despiden toda vez que pertenecen al turno de la defensa, al momento serio donde los haya del elogio tanto de la obra como de la recepción ideal. La conclusión no puede ser otra sino que hay una muy considerable distancia, y no sólo temporal, entre lo expuesto en el prólogo y en el primer acto.

\section{CARTA A UN SU AMIGO.}

Es aquí y en las Coplas en acrósticos donde la razón de la ambigüedad se presenta insondable. Dando por sentado que en parte sea deliberada, no se debe desestimar la posibilidad de que alguna se deba a la complicada historia del texto. La filiación textual de Celestina está sujeta a un proceso de amplificación nada sencillo. La Carta y las Coplas faltan en la edición de la Comedia de Burgos, 1499. Las Coplas presentan muchas y conflictivas variantes en la edición de la Tragicomedia de Valencia, 1514 (la que suele aceptarse como la más esmerada y, quizá, la que reproduce la edición princeps). El Prólogo no aparece en ninguna de las tres ediciones de la Comedia. No sabemos con certeza quién escribe cada parte y a quién se deben las variantes introducidas en algunas de las versiones de una Tragicomedia en que, por si fuera poco el enredo, hasta los impresores pudieran tener su parcela de protagonismo.

Esta complejidad textual contribuye a una sucesiva ambigüedad que se considera definitiva ya en las versiones últimas. Y hacer de éstas un modelo para la exposición de las contradicciones de Rojas es presuponer, sin remisión, que todas las partes y todos los añadidos se deben a él. Por eso toda cautela es poca, y hasta que no se produzcan mejoras en la crítica textual de la obra no

${ }^{42}$ Enrique de Villena, Tratado de consolación, ed. Derek C. Carr (Madrid: Clásicos Castellanos, 1976), 16. 
saldremos de una dinámica de estudio cuyos resultados siempre tendrán el marchamo de provisionales. Pero es preciso hacer justicia: la precaución, menos mal, jamás ha significado renuncia a enfrentarse con los problemas.

Esto es precisamente lo que ha hecho Emilio de Miguel Martínez en su último trabajo sobre Celestina. Partidario decidido de una única autoría, no rehúye ninguna de las tradicionales y enrevesadas cuestiones que afectan a $\tan$ debatido asunto. Como se podrá suponer, su tesis no concuerda con lo expuesto en este artículo, aunque, bien mirado, aquí se está tratando un aspecto de desavenencia temática no usual en la crítica relativa a la autoría de la obra. Su propuesta es la siguiente:

Entendiendo la Carta como un ensarte de tópicos literarios, apunto básicamente que pueden subyacer aquí la afirmación de que la ideación del argumento general y del conjunto de la obra - excepción hecha de los cinco actos que la convertirán en Tragicomedia - y aun el inicio de su escritura (lo que acabaría siendo el acto I) constituyen una primera fase creativa ( $y$ eso se confiesa mediante la utilización del topos del autor antiguo), mientras que su ejecución definitiva pertenece a una fase posterior: los 15 actos de la primitiva Comedia se han escrito en una segunda sesión (topos de su redacción en 15 días de vacaciones. (' $L a$ Celestina'de Rojas, 303)

Al margen de que se comparta o no el grueso de sus conclusiones, no cabe duda de que la revisón crítica que hace de Miguel aviva el rescoldo de una polémica que algunos quisieron zanjada. Hubo unos años recientes en que se habló de una obsesión en la crítica por localizar y desentrañar ocultas alusiones. No había, según algunos, que hacer cábalas o ver velos de Maya donde sólo había afirmaciones expresas que de por sí merecían el beneficio de la credibilidad. A nadie se le oculta que esta presunción de inocencia es válida en muchísimos casos, pero en Celestina tiene poca probabilidad de triunfo. Otra cosa, y muy distinta, es estimar que la inconsistencia de sus prolegómenos sea exclusiva responsabilidad de Fernando de Rojas. Porque mal que nos pese, no podemos dar un paso más allá de la conjetura, más o menos argumentada, pero conjetura al fin.

En consecuencia con lo que se ha venido viendo en páginas precedentes, algunos de los temas tratados por Emilio de Miguel pueden adquirir un diferente tono interpretativo a la luz de aquella falta de concordancia temática entre el acto I y el resto de la obra. Y aunque esto es algo que no se va a desarrollar en este trabajo, quisiera tratar un efecto provocado curiosamente por la misma ambigüedad de las partes 
extradramáticas. Porque si hacemos de Rojas un constructor de calculada contradicción, ello implica una recepción muy concreta y por supuesto nada ambigua: aquella que ha de dilucidar con exactitud los límites del engaño. Esta condición contiene en sí un lector tan sumamente experto como para que discierna en todo momento cuál es la verdad agazapada. La mínima duda, el más leve paso en falso daría por tierra con el entramado perfecto y sin fisuras de la simulación. Si por algún motivo este privilegiado y exclusivo lector lee literalmente donde no debiera, el proceso de significación se orientaría hacia una distorsionada vía que entraña una constante reinterpretación de los contenidos. Una cosa es lanzar un guiño a un lector considerado capaz de recogerlo, ofrecerle un enigma que estimule la lectura, jugar con usos y procedimientos compartidos, y otra encerrarle en un círculo de críptica e irresoluble polisemia. Además, referido ya al tema que nos ocupa, este protolector tendría que desentrañar toda clase de conflictos, por complicados que éstos fueran. Y no un modélico hermeneuta, sino cualquier escolar de los que rodeaban a Rojas estaría al cabo de que en el acto I se abordaban dilemas de espinosa solución.

Se inicia la carta remitida a un amigo dibujándonos a un indolente Rojas que, mano en la mejilla, cavila la necesidad de dar a conocer al mundo una obra hallada. Es un ademán muy semejante al que, algo más de un siglo más tarde, Cervantes adoptará en la demanda de un prólogo que se le resiste. A renglón seguido, Rojas describe las cualidades del acto supuestamente encontrado, pero de lo dicho por él difícil es deducir que en verdad se esté refiriendo a la obra del antiguo autor. Valora positivamente en aquélla a "unos claros ingenios de doctos varones castellanos" de los que extrae las armas defensivas para hacer frente a un posible achaque de amor de su amigo.

Es una forma de justificar la causa de su empresa y la utilidad de su cometido. Recurso viejo y bien conocido, pero... ¿quiénes son esos castellanos del primer acto?, ¿de qué armas habla?, ¿alude a las fuentes del primer autor?, ¿defensivas armas para resistirlos fuegosdel amor cuando allí hemos visto que lo único válido, por exclusión de los saberes, era la experiencia de una vieja tercera?, ¿por qué no hay la más mínima certeza acerca del motivo principal de la Carta, es decir, el arranque del libro? Es posible explicar estas incertidumbres aceptando que el contenido del primer acto ha quedado para Rojas por completo difuminado frente a la totalidad de la Comedia, que es, como se ha dicho, a la que en realidad se refiere. ${ }^{43}$

También en la Carta figuran los más famosos quince días de la

${ }^{43}$ J. R. Stamm, La estructurade "La Celestina":una lectura analítica (Salamanca: Universidad, 1988), 17. 
literatura española, los que dice Rojas que tardó en continuar Celestina.Dos semanas que han provocado la escama de casi todos. Por descontado que interpretaciones no faltan: recurso retórico, concesión al tópico de la confutatio, vacaciones de un profesional del Derecho ya establecido, burla de un lugar común usado por los autores de comedias humanísticas, topos de los quince actos de la Comedia, traducción de un texto latino o tal vez italiano. ${ }^{44}$

De cualquiera de las maneras, tan pequeño periodo de tiempo ha desencadenado que se ande sobre aviso de casi todo lo que Rojas dice en Carta, Prólogo y Coplas en acrósticos. Y lo más curioso es que en el meollo del asunto está lo inconcebible que nos resulta su afirmación. Si Rojas hubiera incrementado la exageración reduciendo el tiempo a una semana, a dos días o a un santiamén, la duda de su veracidad en otros sitios no se vería eliminada, pero sí probablemente disminuida. Lo que es palpable es que Rojas es bastante arbitrario cuando maneja cantidades: "quinze días de unas vacaciones," "leílo tres o cuatro vezes," "gran copia de sentencias entrexeridas," "vi que portaba sentencias dos mil."

También ha dado que hablar esta última hipérbole de la octava de las Coplas en acrósticos. Dos mil es una cantidad tan precisa como quince. Y si para ésta sólo abrigamos duda, para aquélla otro tanto de lo mismo. Así pues, se ha argüido que, aun aceptando la intensidad ponderativa, la cantidad en cuestión es un exceso que no se ajusta con lo que uno se pueda encontrar en el acto primero (E. de Miguel, 319). Pero esto ya es dar pábulo a que la desconfianza penda desacreditadora sobre cada una de las palabras de Rojas, y hartas veces de forma infundada.

Lo primero porque poco de lo que se lee en la Carta se adecúa a lo que vendrá poquísimas páginas después. Y es de rigor insistir una vez más en que su razón es dar noticia de esas páginas halladas y continuadas. Lo segundo

44 Considerado un recurso retórico (Menéndez Pelayo, Origenes de la novela [Madrid-Santander: CSIC, 1943], III:256); confutatio (C. Nepaulsingh, "The Rhetorical Structure of the Prologue to the Libro de Buen Amor and the Celestina,"Bulletin of Hispanic Studies 51 (1974), 325-334); "vacaciones" (Marciales, I:270-271); autores de comedias humanísticas (Russell ed., 186n24); Di Camillo me hace saber que la idea de escribir la obra en quince días ya aparece en el prólogo de Cauteriaria de Barzizza;topos de los 15 actos (E. de Miguel, 303); traducción del latín (Ottavio Di Camillo, "When and Where was the First Act of La Celestina Composed. A Reconsideration," conferencia leída en la Universidad de Boston en Octubre de 1996. Di Camillo considera que la Carta y el Primer Acto son una trad. del latín, aunque sin desestimar la posibilidad de una trad. del italiano, llevada a cabo durante las últimas décadas del siglo XV. Quiero agradeceral autor el envío de su borrador, así como sus comentarios y sugerencias. 
porque el total de refranes, sentencias y proverbios del acto I asciende a 82 , con diferencia el más nutrido de toda la Tragicomedia.$^{45}$ Lo tercero y último porque es muy comprensible la lectura hecha por Alfonso Ordónez, traductor de la edición italiana que suele aceptarse, desde Norton, ${ }^{46}$ como la más vieja versión conservada de la Tragicomedia (Roma, 1506): el verso de la octava "vi que portaua sentencias dos mill" es allí trasladado a "Vedo che porta piu duna sententia".$^{47}$ Por lo demás, y recogiendo bártulos, es este un tema que excede los límites de lo planteado en el presente trabajo, pues lo único que en justicia con él se aviene es, de nuevo, el desajuste producido entre la Carta y el primer acto.

Recientemente Domingo Ynduráin concluía que el descubrimiento de la literatura en el Renacimiento español fue el resultado de la tensión existente entre doctrina y experiencia. ${ }^{48}$ Esta relación conflictiva es el fundamento de nuestro primer acto. Celebérrimo acto del que no podemos decir con seguridad a quién fue debido. Acaso Rojas continuó lo que él mismo había escrito en otro tiempo, quién sabe; pero si así fue, desde luego el conflicto inicial no tuvo resolución en sus manos, o tal vez sí en un desvío hacia derroteros menos intrincados. A fin de cuentas la conclusión trágica evita el riesgo de una interpretación en exceso controvertida. Un final feliz hubiera implicado lecturas más conflictivas, menos tendentes al orden que supone la desgracia y la muerte de muchos de los partícipes en la historia amorosa. E incluso el amor, hilo maestro de la historia, parece en las primeras páginas un escenario, un decorado de fondo donde prorrumpe el desacato a los códigos de la Antigüedad para en su lugar instaurar, preeminente, la experiencia de lo vivido.

${ }^{45} \mathrm{~J}$. Gella Iturriaga, "444 refranes de La Celestina," en "La Celestina" y sucontorno social, 246-249.

${ }^{46}$ F. J. Norton, Printing in Spain 1501-1520 with a Note on the Early Editions of the "Celestina" (London: Cambridge UP, 1966), 155.

${ }^{47}$ K. V. Kish, An Edition of the First Italian Translation of the 'Celestina' (Chapel Hill: U North Carolina P, 1973), 37. Igual en la versión de Milán, 1514 (Tragicocomedia di Calisto e Melibeade Lingua Hispana in Idioma Italico Traducta [Milano: Zanotto da Castione, 1514], sign. Biii, recto).

${ }^{48}$ Domingo Ynduráin, El descubrimientode la literatura en el Renacimiento español. Discurso leido ante la Real Academia Española... (Madrid: RAE, 1997). 